\title{
A Basic Research for Preservation of Works Exhibited in the Outdoor Sculpture Park - A Scientific Analysis of Painted Work 'Conversion' Exhibited in the Cheonmasan Sculpture Park -
}

\author{
Seung-Jun $\mathrm{Oh}^{1}$, Koang-Chul $\mathrm{Wi}^{2,{ }^{*}}$ \\ ${ }^{1}$ The Research Center of Conservation Science for Cultural Heritage, Hanseo University, Seosan 31962, Korea \\ ${ }^{2}$ Department of Cultural Heritage Conservation, Hanseo University, Seosan 31962, Korea
}

\author{
Received August 6, 2021 \\ Revised August 13, 2021 \\ Accepted August 17, 2021 \\ *Corresponding author \\ E-mail: kcwi@hanseo.ac.kr \\ Phone: +82-41-660-1043 \\ Journal of Conservation Science \\ 2021;37(4):391-401 \\ https://doi.org/10.12654/JCS.2021. \\ 37.4 .08 \\ pISSN: 1225-5459, eISSN: 2287-9781 \\ (c) The Korean Society of \\ Conservation Science for Cultural \\ Heritage \\ This is an Open-Access article distributed \\ under the terms of the Creative \\ Commons Attribution Non-Commercial \\ License (http://creativecommons.org/ \\ licenses/by-nc/3.0) which permits \\ unrestricted non-commercial use, \\ distribution, and reproduction in any \\ medium, provided the original work is \\ properly cited.
}

\begin{abstract}
Outdoor sculptures of modern art works are being damaged and deteriorated as they are exposed to the outdoor environment due to the nature of exhibition in the outdoor environment, but secure of basic data through the measures for conservation and advanced researches still remain in the early stage. The surface of "Conversion" which is exhibited in the Busan Cheonmasan Sculpture Park has been exfoliated and deteriorated due to outdoor exhibition for a long time, so systematic conservation and management of works are considered necessary. Prior to the conservation and management, this study conducted observation of cross section, analysis of inorganic components, FT-IR, Raman and Py-GC/Mass analysis to examine the nature and type of paints used for the work through a scientific analysis. As a result of analysis, paints used for the "Conversion" include paint mixed with silvery aluminium powder and white pigment, reddish paint mixed with toluidine red, bluish paint that mixed prussian blue and titanium white and mixture of phthalocyanine blue and titanium white. The result is expected to be used as basic data for selecting materials necessary for conservative treatment of and establishing a plan for conservative treatment of the "Conversion".
\end{abstract}

Key Words Outdoor sculptures, Outdoor painted works, Analysis of paint, Conservation of outdoor sculptures, Analysis of painting

\section{INTRODUCTION}

Traditionally, painting, plating and dye using natural resin or pigment and animal protein collected from minerals were used as materials for painting, but was developed as the type similar to the present paint around the $18^{\text {th }}$ century and started to change significantly as nitrocellulose was synthesized and applied as lacquer after 1920 (Son and Lee, 2008). After that, vinyl resin paint, epoxy resin paint and emulsion resin paint based on the synthetic resin which was developed indebted to the drastic development of petrochemical industry were developed and started to be put to practical use and generalized not only for buildings and craftworks but for the whole industries.

Painting aims to protect objects due to the characteristics of rust resistance, water resistance, chemical resistance, oil resistance, heat resistance and weatherproofing using hardened paint film by spreading paint evenly to the object of painting. Painting is also used for buildings, environmental sculptures and outdoor sculptures as it alleviates fatigue of human body and improves working environment and living space or heightens aesthetic effect by coloring through the mixture of pigments (Kim, 2014).

Paints used for painting are divided largely into the water paint that use by mixing water and oil paint used by diluting 
with volatile solvent. Although water paint has advantages for convenient painting and rapid drying speed, it has mostly been replaced by synthetic resin emulsion for its weak durability and water resistance. On the other hand, oil paint, in spite of relatively slow drying speed and shortcomings of harmfulness and flammability caused by use of volatile solvent, can be used for various objects such as metals and woods unlike water paint that use and scope of application are limited, and has advantages of varied materials such as lacquer, urethane, epoxy and enamel with wide scope of color selection.

Due to the nature of manufacturing using various materials, outdoor sculptures are mostly painted with oil paint. Liquid painting is a method of painting with a brush or roller and spraying with an air spray gun by mixing paint with volatile solvent, and is painted in order of surface treatment and putty of object, cleaning, degreasing and primer coating for improving adhesive strength of pigment before painting. Next steps include color selection, intermediate coating to adjust thickness of coating and top coating for covering a protective film. While the aforementioned painting work has the advantage of uniform application suited to the characteristics of various-shaped sculptures without blanks, but is painted manually and has a disadvantage of dripping down. Despite secondary coating is made, there is still a drawback of discoloration or coming off by scratches for its weak durability.

Painting treatment is the most common way for sculptures made with carbon steel as a main material to prevent rust and satisfy aesthetic element, but iron which was painted initially starts to be corroded again due to the limit of durability of paint and occurrence of discoloration, bleach, peeling off, exfoliation by air pollutants, moisture, ultraviolet rays, acid rain etc (Considine et al., 2010). which can become a structural problem if it is left unattended. Especially, the degree of damage of works exhibited in the sculpture parks that are being exposed to the outdoor environment for a long time become severe with the passage of time, so conservative treatment through repainting is carried out to prevent the foregoing and preserve works (Kang et al., 2016).

Due to the nature of painted sculptures, it is necessary to select a color to be applied for conservative treatment, but restoration of the color of paint which is discolored bleached by lengthy outdoor exposure is not an easy process (Kwon et al., 2016). Restoration may be possible if the data at the time of manufacturing is recorded or through communication with artist, but painting is carried out by the facility specialized in treatment and communication with artist is difficult at times, and it is the reason why restoration of color is the most urgent and difficult.

A study related to the preservation of current outdoor painting sculptures or sculptures is a scientific analysis of the types of paint and painting techniques used in the F-51D Mustang Fighter, Registered Cultural Heritage No. 666, by Kang et al. (2020), Kim et al. (2012), analysis of the paint used for the Registered Cultural Heritage Tank No. 381, Kang et al. (2016), analysis of the characteristics of the paint used for the 6.25 war defense equipment in the War Memorial of Korea, Kim et al. (2016), a rickshaw for modern and modern cultural properties Analysis of the painting layer used in Huh (2009), analysis of painting technique used in Alexander Calder's 'Untitled-Swiss Cheese' painting sculpture by Huh (2009), Nicky de Saint-Phalle 'Black Nana' painting sculpture by Kwon et al. (2016) Research on the type of paint and painting technique used in the painting, and the scientific analysis of painting sculptures exhibited at the Jeonbuk Sculpture Park by Oh and Wi (2020), has been advanced, but this is not the case with registered cultural assets, specific artists, or painting works on display at national and public art museums. Scientific analysis and research on painting works on display in outdoor sculpture parks are only in the early stages because of their limited application. In addition, since the characteristics of painting using paint vary depending on the artist, period, painting company, and material selection, continuous and extensive research and construction of basic data are required. We intend to build data that can be used as basic data for future conservation treatment through scientific analysis before it is completely decomposed to an impossible degree.

\section{OBJECT AND METHOD OF ANALYSIS}

\subsection{Object of analysis}

Object of analysis is the "Conversion" exhibited in the Busan Cheonmasan Sculpture Park and the artist $\mathrm{Na}$ Myeong-gyu installed in 2003 assuming a three-dimensional formation using circle, triangle and quadrangle and meant to enable children to experience of materiality and quantitative sense from the color of taegeuk (yin-yang symble) spatial 


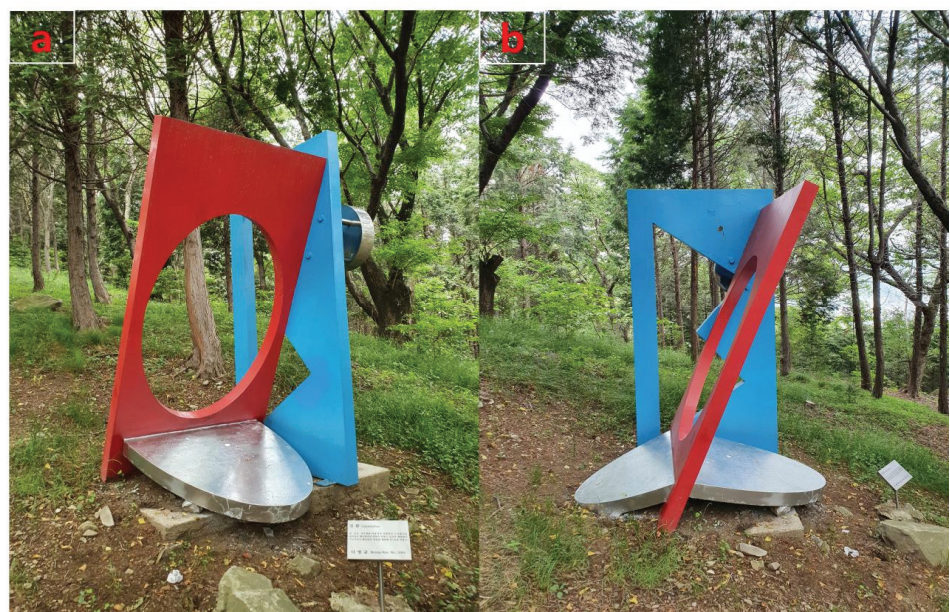

Figure 1. Analyzed sculpture works. (a) Front of the work. (b) Aspect of the work.

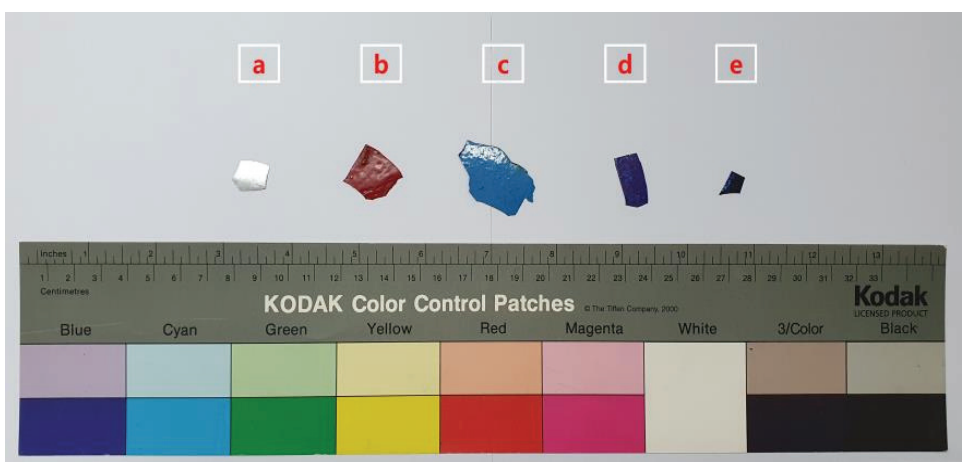

Figure 2. Analysis sample collection. (a) Silver paint sample. (b) Red paint sample. (c) Blue paint sample (c-1). (d) Blue paint sample (c-2), (e) Blue paint sample (c-3)).

pattern of the work. The sculpture selected for this study is the work that analysis sample can be collected as the paint applied on the surface has been peeled off and exfoliated by outdoor environment (Figure 1a, b), and this study collected only a small quantity of sample that was exfoliated completed from the work and fell to the ground not to cause damage to the work (Figure $2 \mathrm{a} \sim \mathrm{e}$ ), and conducted analysis dividing specimen of the work painted with 3 colors into silver (hereafter Specimen a), red (hereafter Specimen b), blue (hereafter Specimen c). As for blue color, 3 painted layers were observed with naked eyes and this study separated the layers as the outermost painted layer (hereafter c-1), intermediate layer(hereafter c-2) and layer that is closest to the surface of object (c-3). Silver and red samples, excluding blue color, were not physically separable, but were analyzed using peeled and ground-based samples, and silver and red specimens were studied through analysis results.

\subsection{Method of analysis}

\subsubsection{Observation of cross section}

This study grinded collected sample using a grinder with \#400 \#4000 sandpaper, grinding cloth and DP-Suspension solution after ultrasonic cleaning and drying and mounting with $2 \mathrm{~K}$ epoxy resin. After grinding, this study manufactured a sample after removing alien substances in the ultrasonic cleaning machine replacing distilled water several times, and observed and took a photo of the sample under reflected light using an optical microscope(AxioImager $\mathrm{A} 2 \mathrm{~m}^{\mathrm{TM}}$ Upright Microscope, Zeiss, Germany). 


\subsubsection{Analysis of inorganic components}

To identify the composition of inorganic components included in the paint of the work, this study conducted analysis using an energy-dispersive analyzer installed in the scanning electron microscope. After carrying out gold coating on the sample manufactured for observation of cross section, this study conducted analysis using energy dispersive spectrometer (EDS, AZtecOne with Xplore Compact, Oxford) combined with a scanning electron microscope (EM-30AX, COXEM, Korea) and setting acceleration voltage as $20 \mathrm{kV}$ and time of analysis as $90 \mathrm{sec}$.

\subsubsection{Infrared spectroscopic analysis}

Analysis was conducted using ATR method for nondestructive analysis of surface with a small quantity of samples, which was conducted targeting the outermost surface of each sample, in other words the surface of painted layer. IRSpirit of SHIMADZU was used as an analyzer with the range of 4000 $\sim 500 \mathrm{~cm}^{-1}$, and resolution was $4 \mathrm{~cm}^{-1}$ and scan time was 24 times. As for the obtained spectrum, this study searched for the information through the library inside the software.

\subsubsection{Raman spectroscopic analysis}

Raman (RAMANtouch, Nano photon, Japan) analysis was conducted with $60 \mathrm{mV}$ diode laser having wavenumber 2200 $\sim 200 \mathrm{~cm}^{-1}$, resolution $8 \mathrm{~cm}^{-1}$ and illuminant $785 \mathrm{~nm}$ of wavelength, and this study analyzed paint through comparison with reference. The detailed analysis conditions are Laser $532 \mathrm{~nm}$, Grating $600 \mathrm{gr} / \mathrm{mm}$, Spatial resolution (X: $0.35 \mu \mathrm{m}) \times(\mathrm{Y}: 0.5 \mu \mathrm{m}) \times(\mathrm{Z}: 1.0 \mu \mathrm{m})$, and Grating: $600 \mathrm{gr} / \mathrm{mm}$.

\subsubsection{Pyrolysis gas chromatography/Mass spectrometry}

This study used Gas Chromatography-Mass (JTD-505 III + ISQ 7000, Agilent, USA) which is equipped with a Pyrolyzer (PY-3030S, Frontier Lab, USA). Analytical conditions for GC/MS were set as column HP-5 ms (30 m $\times$ $0.25 \mathrm{~mm} \times 0.25 \mathrm{~m}$ ), gas flow $1 \mathrm{~mL} / \mathrm{min}$, oven tempp. 50 $\sim 300^{\circ} \mathrm{C}\left(10^{\circ} \mathrm{C} / \mathrm{min}\right)$ and split ratio $50: 1$, mass range 50 $\sim 500$, and set Pyrolyzer as sample weight $1 \mathrm{mg}$, furnace $700^{\circ} \mathrm{C}$ and interface $320^{\circ} \mathrm{C}$ in the way of single-shot. Specimens $\mathrm{a}$ and $\mathrm{b}$ were pyrolyzed over all layers without separate physical layer separation, and blue series specimens of c-a, c-2, and c-3 were partially separated, resulting in thermal decomposition for each layer.

\section{RESULT OF ANALYSIS AND CONSIDERATION}

\subsection{Observation of cross section}

As a result of examination on the cross section of painted layer with optical microscope, Sample a was confirmed to be 6 layers from the surface of object including putty layer, and primer is assumed to be painted using putty to reinforce adhesive strength of intermediate coat. And 3 layers that are assumed to be repainted were also confirmed, and the area is also judged to be repainted twice after putty work (Figure $3 a)$. Figure $3 b$ shows the result of observation of the cross section of Sample b, and 10 layers were confirmed specifically, but those layers are assumed to be repainted 2 $\sim 3$ times. It is assumed that repetitive painting was made 2 times at the time of primary painting after putty work, and repainting process was conducted again from the stage of

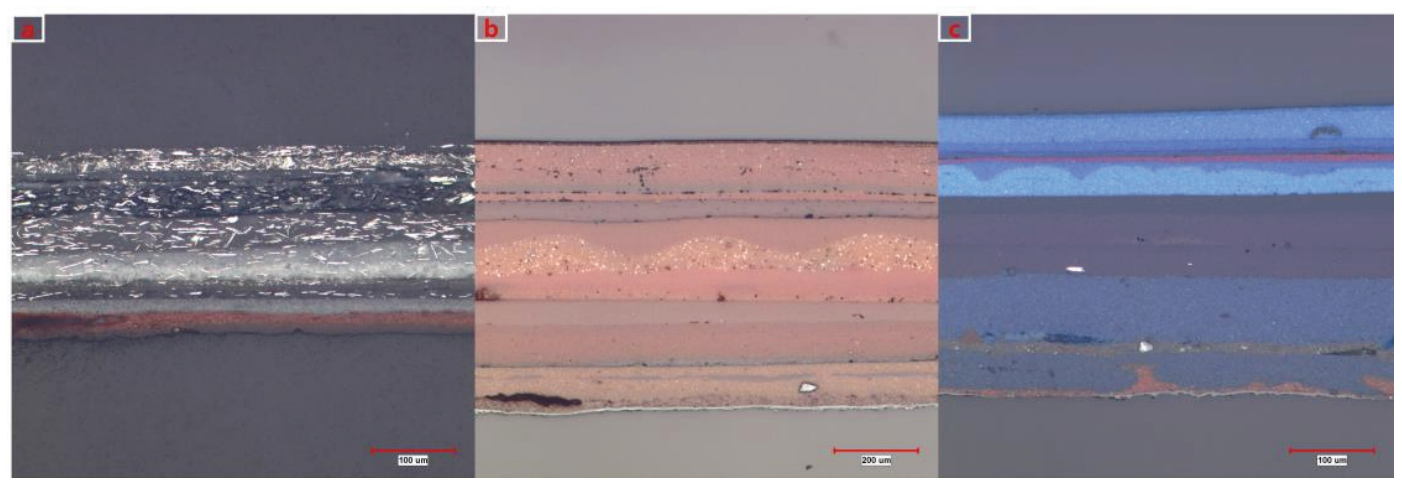

Figure 3. A photograph of cross section of a paint layer. (a) Silver paint layer. (b) Red paint layer. (c) Blue paint layer. 
putty work after 2 times of additional repainting. It is also assumed that repainting was conducted from putty work upon completion of additional repainting for 2 times. The foregoing can be assumed based on the layer that underwent putty work in the intermediate layer is observed and painted layer with similar colors is repeated.

Sample c is confirmed to have total 13 layers, and is assumed that primary painting was conducted after putty work on the surface of object, and painting for $2 \sim 3$ times was made using a paint with similar color. It is also considered that repainting including putty work was conducted for $1 \sim$ 2 times and the outermost painted layer was painted $1 \sim$ 3 times (Figure 3c).

As a result of observation of the cross section using BEI (backscattered electron image) of electron microscope (Figure 4), a relatively bigger and irregular-shaped particles are observed in the painted layer that is assumed to be putty, and particle with relatively bright color is scattered. As for Sample a, it was confirmed that the thickness of painted layer that is closest to the object was $18.4 \sim 30.4 \mu \mathrm{m}$, and primary coated layer of the layer that was painted at the time of secondary repainting was $22.4 \sim 23.6 \mu \mathrm{m}$ and the thickness of secondary coated layer was $19.2 \sim 19.9 \mu \mathrm{m}$, showing that the object was painted relatively uniformly (Figure $4 a$ ).

This study also confirmed that the layer just above putty layer out of painted layers that are closest to the object of Sample b was painted repeatedly for 2 times, and the thickness of primary painted layer was $91.8 \sim 96.7 \mu \mathrm{m}$ and secondary painted layer was $60.1 \sim 61.7 \mu \mathrm{m}$ respectively, showing that primary painting was thicker than secondary painting. It is also assumed that additional painting after that, and the thickness of painted layer was $60.9 \sim 74.7 \mu \mathrm{m}$ showing relatively nonuniform painted layer as additional painting was made without putty work. Newly-painted layer was confirmed to be painted additionally for 3 times after putty work (Figure 4b).

As for Sample c, it is assumed that painting was conducted one time after putty work and additional painting was made using a paint with similar color after a specific period of time. It is considered that additional painting was conducted at least more than 3 times for a certain period of time.

Painted layer was confirmed to have uniform thickness as 34.5 $\sim 35.5 \mu \mathrm{m}$ and $19.5 \sim 22.0 \mu \mathrm{m}$. It is assumed that repainting was carried out most recently including putty work, and painting was made for $2 \sim 3$ times above the putty layer (Figure $4 \mathrm{c}$ ).

\subsection{Energy dispersive $X$-ray spectroscopy analysis}

This study conducted analysis of inorganic components using EDS attached to SEM, and the analysis was carried out targeting all samples in order of internal to external painted layers based on the layer close to the surface of sculptures, and analyzed each putty layer targeting the area where bright particle is shown as scattered shape on the electron microscope. We also conducted a face analysis for each floor.

As a result of analysis on the Sample a, $\mathrm{Mg}, \mathrm{Al}, \mathrm{Si}$ and Ti were detected from putty layer located between putty layer and painted layer that are the closest to the surface of the work, it is judged that putty having kaolin(kaolinite $\mathrm{Al}_{2} \mathrm{O}_{3}$. $2 \mathrm{SiO}_{2} \cdot 2 \mathrm{H}_{2} \mathrm{O}$ and halloysite $\mathrm{Al}_{2} \mathrm{O}_{3} \cdot \mathrm{SiO}_{2} \cdot 4 \mathrm{H}_{2} \mathrm{O}$ ), white titanium dioxide $\left(\mathrm{TiO}_{2}\right)$ and talc $\left(3 \mathrm{MgO} \cdot 4 \mathrm{SiO} \cdot \mathrm{H}_{2} \mathrm{O}\right)$ as ingredients was used. Considering that the first painted layer has high in $\mathrm{Mg}$ and $\mathrm{Ti}$, it is assumed that it used mixture of extender pigment and white pigment, and is judged that the paint used for subsequent repainting has materials that mixed aluminium powder with white pigment having $\mathrm{Al}$ and Ti as main ingredients (Table 1).

It is assumed that main ingredients of the first putty layer

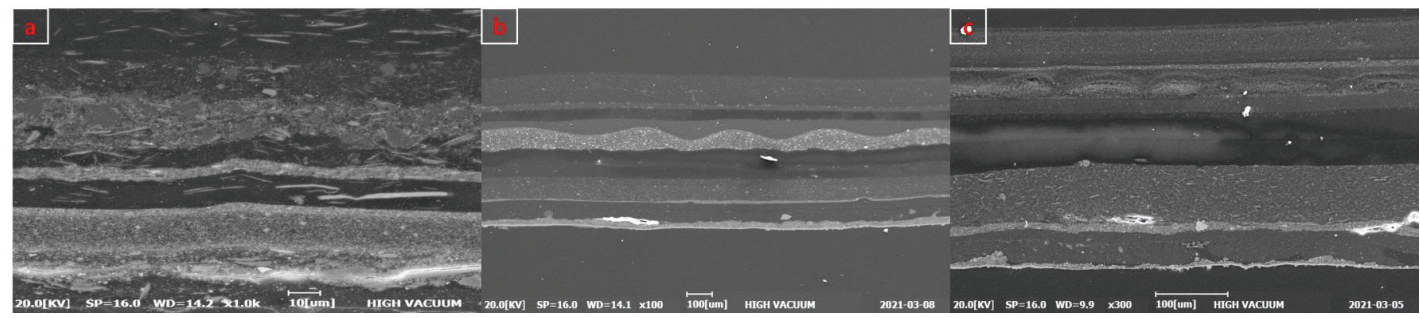

Figure 4. Photo of sectional observation by scanning electron microscope. (a) Silver paint layer. (b) Red paint layer. (c) Blue paint layer. 
of Sample b are $\mathrm{Ca}$ and $\mathrm{Si}$, so it used calcium carbonate $\left(\mathrm{CaCO}_{3}\right)$-based materials, and $\mathrm{Si}$ was detected as a main ingredient from 3 layers painted on it, so it was difficult to assume which mineral pigment was mixed. However, Fe was detected from the last layer, which is assumed to be red iron oxide. From the putty layer that is assumed to be conducted for the subsequent repainting, $\mathrm{Si}$ was detected, and $\mathrm{Si}, \mathrm{Al}$, $\mathrm{Ca}$, Ti were detected as main ingredients from the painting on the intermediate layer and $\mathrm{Fe}$ was identified partially, but due to the difficulties in assuming a specific mineral pigment, this study intends to compare comprehensive with FT-IR and result of Raman spectroscopic analysis (Table 2).

Total 13 painted layers were identified in the Sample c, and it is assumed that it used putty having white titanium dioxide $\left(\mathrm{TiO}_{2}\right)$ and talc $\left(3 \mathrm{MgO} \cdot 4 \mathrm{SiO} \cdot \mathrm{H}_{2} \mathrm{O}\right)$ as ingredients because $\mathrm{Mg}, \mathrm{Si}, \mathrm{Ti}, \mathrm{Fe}$ were detected as main ingredients from the first putty layer. The second putty layer is assumed to use putty containing (kaolin, kaolinite $\mathrm{Al}_{2} \mathrm{O}_{3} \cdot 2 \mathrm{SiO}_{2}$. $2 \mathrm{H}_{2} \mathrm{O}$, halloysite $\mathrm{Al}_{2} \mathrm{O}_{3} \cdot \mathrm{SiO}_{2} \cdot 4 \mathrm{H}_{2} \mathrm{O}$ ), white titanium dioxide $\left(\mathrm{TiO}_{2}\right)$ and talc $\left(3 \mathrm{MgO} \cdot 4 \mathrm{SiO} \cdot \mathrm{H}_{2} \mathrm{O}\right)$ as ingredients as $\mathrm{Mg}, \mathrm{Si}, \mathrm{Ti}, \mathrm{Fe}$ and $\mathrm{Al}$ were detected. And only $\mathrm{Si}$ and Ti were detected from the third putty layer, so it is assumed that the layer was painted using materials that mixed aluminium powder with white pigment as a main ingredient. As for the paint layers, $\mathrm{Fe}, \mathrm{Ti}, \mathrm{Al}, \mathrm{Si}$ and $\mathrm{Mg}$ were detected from the second to the fifth layer, so it is judged that painting was conducted using a paint that mixed deep blue mineral pigment and white titanium dioxide $\left(\mathrm{TiO}_{2}\right)$ with iron (II)-ferrocyanide as a main ingredient. From the blue paint layer, $\mathrm{Si}$ and $\mathrm{Al}$ that can be assumed as ultramarine $\left(\mathrm{Na}_{6} \mathrm{Al}_{6} \mathrm{Si}_{6} \mathrm{O}_{24} \mathrm{~S}_{4}\right)$ were detected partially, but because $\mathrm{Cu}$ which is an ingredient of organic phthalocyanine pigment was detected partially, so this study intends to compare with FT-IR and result of Raman spectroscopic analysis (Table 3).

However, although most of the putty work is collectively processed throughout the work to evenly represent the paint layer, the analysis of samples taken from one work showed that the first putty layer, which is close to the foundation, is different. It is believed that the specimen may have been contaminated using specimens that were already peeled off during the sample collection process, and that reproducibility should be secured through repeated analysis.

Table 1. Result of inorganic component of the sample of A (a)

\begin{tabular}{rlccccccccc}
\hline \multirow{2}{*}{ Samples } & \multicolumn{8}{c}{ Elements (wt\%) } \\
\cline { 2 - 10 } & & $\mathbf{C}$ & $\mathbf{O}$ & $\mathbf{M g}$ & $\mathbf{S i}$ & $\mathbf{A l}$ & $\mathbf{C a}$ & $\mathbf{T i}$ & $\mathbf{F e}$ & $\mathbf{C u}$ \\
\hline \multirow{3}{*}{ Outside } & Painted layer & 32.08 & 20.14 & 7.91 & 17.79 & 6.95 & - & 15.13 & - & - \\
\cline { 2 - 10 } & Painted layer & 32.04 & 23.94 & 7.33 & 17.10 & 5.55 & - & 14.04 & - & - \\
\cline { 2 - 9 } & Putty layer & 40.57 & 26.07 & 3.32 & 15.08 & 2.44 & - & 12.52 & - & - \\
\cline { 2 - 10 } & Putty layer & 30.76 & 32.34 & 3.49 & 15.51 & 2.12 & - & 15.78 & - & - \\
\cline { 2 - 10 } & Painted layer & 28.03 & 28.80 & 9.14 & 14.83 & 1.75 & - & 17.45 & - & - \\
\cline { 2 - 9 } & Putty layer & 31.39 & 27.02 & 7.14 & 13.83 & 2.13 & - & 18.49 & - & - \\
\cline { 2 - 9 } Inside & Putty layer & 32.49 & 27.60 & 6.79 & 13.51 & 1.65 & - & 17.96 & - & - \\
\hline
\end{tabular}

Table 2. Result of inorganic component of the sample of B (b)

\begin{tabular}{|c|c|c|c|c|c|c|c|c|c|c|}
\hline & \multirow{2}{*}{ Samples } & \multicolumn{9}{|c|}{ Elements (wt\%) } \\
\hline & & $\mathrm{C}$ & $\mathbf{O}$ & Mg & $\mathbf{S i}$ & Al & $\mathbf{C a}$ & $\mathbf{T i}$ & $\mathrm{Fe}$ & $\mathbf{C u}$ \\
\hline \multirow{2}{*}{ Outside } & Painted layer & 40.58 & 28.79 & - & 13.82 & 0.75 & 5.50 & 10.56 & - & - \\
\hline & Painted layer & 41.08 & 32.41 & - & 13.46 & 0.77 & 5.14 & 7.14 & - & - \\
\hline \multirow{5}{*}{$\uparrow$} & Painted layer & 39.67 & 33.38 & - & 16.21 & 0.48 & 4.68 & 5.58 & - & - \\
\hline & Painted layer & 44.98 & 34.37 & - & 13.32 & - & 3.21 & 4.12 & - & - \\
\hline & Painted layer & 42.41 & 36.65 & - & 9.96 & - & 2.50 & 4.27 & 4.21 & - \\
\hline & Putty layer & 67.45 & 24.72 & - & 7.83 & - & - & - & - & - \\
\hline & Painted layer & 72.17 & 14.04 & - & 8.32 & - & - & - & 5.47 & - \\
\hline \multirow{3}{*}{ Inside } & Painted layer & 73.47 & 17.41 & - & 9.12 & - & - & - & - & - \\
\hline & Painted layer & 72.31 & 17.87 & - & 9.82 & - & - & - & - & - \\
\hline & Putty layer & 70.58 & 19.60 & - & 6.87 & - & 2.95 & - & - & - \\
\hline
\end{tabular}


Table 3. Result of inorganic component of the sample of $\mathrm{C}(\mathrm{c})$

\begin{tabular}{|c|c|c|c|c|c|c|c|c|c|c|}
\hline & \multirow{2}{*}{ Samples } & \multicolumn{9}{|c|}{ Elements (wt\%) } \\
\hline & & $\mathrm{C}$ & $\mathbf{O}$ & Mg & $\mathbf{S i}$ & Al & $\mathbf{C a}$ & $\mathbf{T i}$ & $\mathrm{Fe}$ & $\mathrm{Cu}$ \\
\hline \multirow{2}{*}{ Outside } & Painted layer & 27.31 & 19.37 & - & 2.18 & - & - & 51.14 & - & - \\
\hline & Painted layer & 17.92 & 14.52 & - & 3.82 & - & - & 55.59 & - & 8.15 \\
\hline \multirow{8}{*}{$\uparrow$} & Painted layer & 12.15 & 11.80 & - & 3.99 & - & - & 72.06 & - & - \\
\hline & Putty layer & 12.19 & 12.11 & - & 4.10 & - & - & 71.60 & - & - \\
\hline & Painted layer & 11.62 & 11.07 & - & 3.34 & 1.06 & - & 72.91 & - & - \\
\hline & Painted layer & 28.48 & 19.96 & - & 1.65 & 0.62 & - & 49.29 & - & - \\
\hline & Painted layer & 25.15 & 18.28 & - & 1.72 & - & - & 54.85 & - & - \\
\hline & Painted layer & 26.27 & 25.11 & 3.52 & 17.71 & 0.42 & - & 15.43 & 10.94 & - \\
\hline & Painted layer & 28.19 & 21.06 & 3.45 & 18.63 & - & - & 17.89 & 10.78 & - \\
\hline & Painted layer & 27.46 & 20.85 & 4.15 & 21.16 & - & - & 14.12 & 12.26 & - \\
\hline \multirow{3}{*}{ Inside } & Putty layer & 20.31 & 19.91 & 5.85 & 25.24 & 1.84 & - & 12.44 & 14.41 & - \\
\hline & Painted layer & 24.32 & 19.72 & 8.13 & 21.81 & - & - & 12.04 & 13.98 & - \\
\hline & Putty layer & 23.98 & 23.16 & 7.52 & 26.55 & - & - & 16.44 & 2.35 & - \\
\hline
\end{tabular}

\subsection{Infrared spectroscopic analysis}

When illuminating analysis sample changing the wavelength of infrared rays, infrared rays of a special category are absorbed depending on the functional grup such as amino group or carbonyl group, and this study searched for infrared rays spectroscopic analysis spectrum that can be used for examining unidentified substance according to intrinsic absorption spectrum (Michele et al., 1999) through the library of software, and analyzed external painted layers of Sample $\mathrm{a}$ and $\mathrm{b}$ that are currently exposed, and external (c-1) and existing painted layer (c-2, c-3) of Sample c that are currently exposed.

Based on the $3642 \mathrm{~cm}^{-1}, 2352 \mathrm{~cm}^{-1}, 1464 \mathrm{~cm}^{-1}, 1091 \mathrm{~cm}^{-1}$ and $873 \mathrm{~cm}^{-1}$ as a result of spectrum search of Sample a, it is assumed that extender pigment was used. As $3424 \mathrm{~cm}^{-1}$, $2850 \mathrm{~cm}^{-1}, 1655 \mathrm{~cm}^{-1}, 1614 \mathrm{~cm}^{-1}, 1506 \mathrm{~cm}^{-1}$ and $1454 \mathrm{~cm}^{-1}$ were confirmed, it appears that painting was conducted using a paint that aluminum power metallic pigment is added, and the result confirms to the result of inorganic components (Figure 5a). Sample b shows the values of $2969 \mathrm{~cm}^{-1}(\mathrm{O}-\mathrm{H})$, $2907 \mathrm{~cm}^{-1}(\mathrm{O}-\mathrm{H}), 1711 \mathrm{~cm}^{-1}(\mathrm{C}=\mathrm{O}), 1472 \mathrm{~cm}^{-1}, 1405 \mathrm{~cm}^{-1}$, $1241 \mathrm{~cm}^{-1}, 1093 \mathrm{~cm}^{-1}, 1015 \mathrm{~cm}^{-1}$ in the painted layer, it is assumed to be polyester resin(Acid-functional Polyester resin) having carboxylic acid group (Figure 5b)(Thomas, 2004). Polyester-based paints are used widely for buildings and sculptures that are installed in outdoors and exposed severely to ultraviolet rays, and the result shows the possibility to assume that the paint was also used for sculptures exhibited in the outdoors. In addition, polyester resin may be an ingredient derived from a clear coat applied to the top layer of the paint face, and the same ingredient is identified in specimens a and c, which are also identified as a result of the collective process of the clear coat work.

In the result of spectrum search, D-Polydiallyl-Phthalate
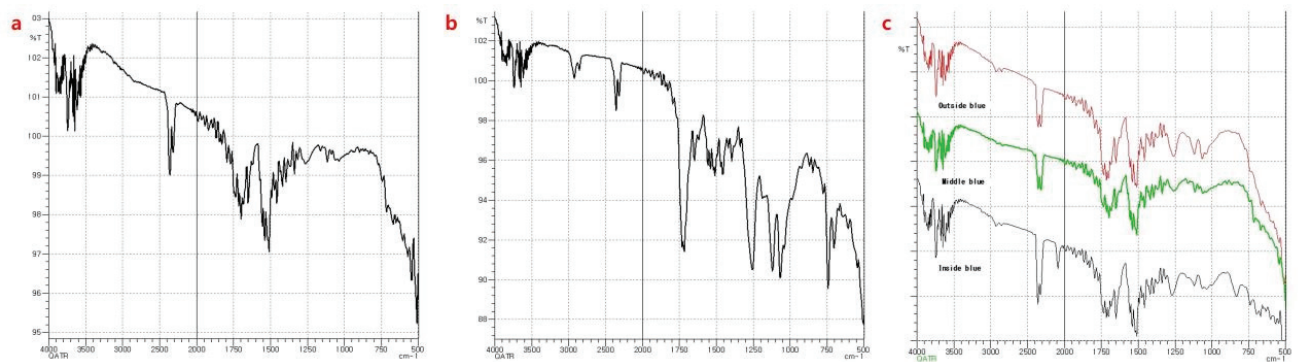

Figure 5. FT-IR Spectra of paint layers. (a) Silver paint layers. (b) Red paint layers. (c) Blue paint layers. 
which is an ingredient that improves flexibility, transparency, durability and conservativeness of paint as a plasticizer was also identified, which supports the assumption. As a result of spectrum search, $3047 \mathrm{~cm}^{-1}, 1611 \mathrm{~cm}^{-1}, 1508 \mathrm{~cm}^{-1}, 1480 \mathrm{~cm}^{-1}$, $1465 \mathrm{~cm}^{-1}, 1421 \mathrm{~cm}^{-1}, 1333 \mathrm{~cm}^{-1}, 1287 \mathrm{~cm}^{-1}, 1120 \mathrm{~cm}^{-1}, 770$ $\mathrm{cm}^{-1}$ and $754 \mathrm{~cm}^{-1}$ were identified in c-1, c-2 and c-3 of Sample c, so it is assumed that painting was conducted using a phthalocyanine blue paint (Figure 5c). And D-PolydiallylPhthalate which is used commonly as plasticizer to improve flexibility, transparency, durability and conservativeness of paint was also identified, so it is assumed that painting was carried out using a paint with functionality.

\subsection{Raman spectroscopic analysis}

As a result of Raman analysis, characteristic peak of N-Benzylethanolamine was identified in the Sample a, but characteristic peak of silver was unidentifiable (Figure 6). As for red, $342.0 \mathrm{~cm}^{-1}, 987.3 \mathrm{~cm}^{-1}, 1126.2 \mathrm{~cm}^{-1}, 1188.0 \mathrm{~cm}^{-1}$, $1330.0 \mathrm{~cm}^{-1}, 1397.9 \mathrm{~cm}^{-1}, 1617.2 \mathrm{~cm}^{-1}$ that are the characteristic peak of toluidine red were confirmed, so it is judged that toluidine red was used for red paint layer (Figure 7). Considering that $680.0 \mathrm{~cm}^{-1}, 746.4 \mathrm{~cm}^{-1}, 1340.2 \mathrm{~cm}^{-1}$, $1447.8 \mathrm{~cm}^{-1}$ and $1528.0 \mathrm{~cm}^{-1}$ that are the characteristic peak of copper phthalocyanine blue are shown in blue, it is judged that copper phthalocyanine blue was used as a blue pigment (Figure $8 \mathrm{a} \sim \mathrm{c}$ ). The value corresponds to the phthalocyanine blue identified in the FT-IR analysis result and $\mathrm{Mg}$ and $\mathrm{Cu}$ detected in the analysis of inorganic components.

\subsection{Pyrolysis gas chromatography/mass spectrometry}

As a result of examining organic pigment assumed

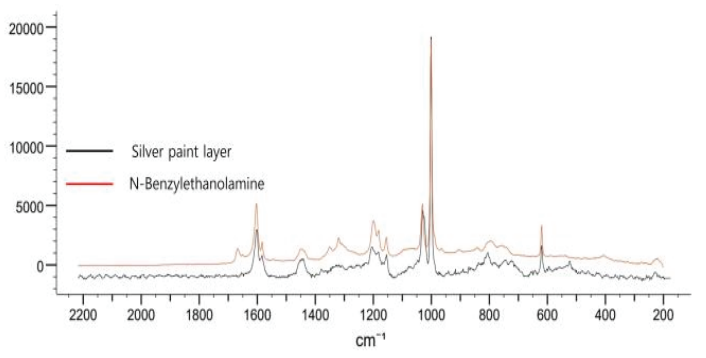

Figure 6. Raman spectra of silver paint layers.

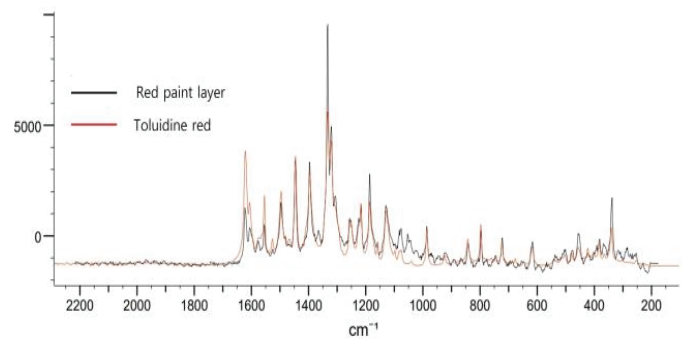

Figure 7. Raman spectra of red paint layers.

through the Raman analysis to identify the types of organic pigment by color, toluen, 1,3,5,7-Cyclooctatetraene, Naphthalene and 2-Benzenedicarboxylic acid were identified in the Sample a (Figure 9), and 2-Butanone, Benzoic acid, Phthalic anhydride and Dibutyl phthalate were measured in the Sample b (Figure 10). In the Sample c-1, c-2 and c-3, Phthalic anhydride, p-Terphenyl, Dibutyl phthalate and 1,4-Benzenedicarboxylic acid were identified (Figure 11 13), but pyrolysis product related to color pigment was not identified in any of 5 samples, so it was difficult to identify if it corresponds to Raman data.
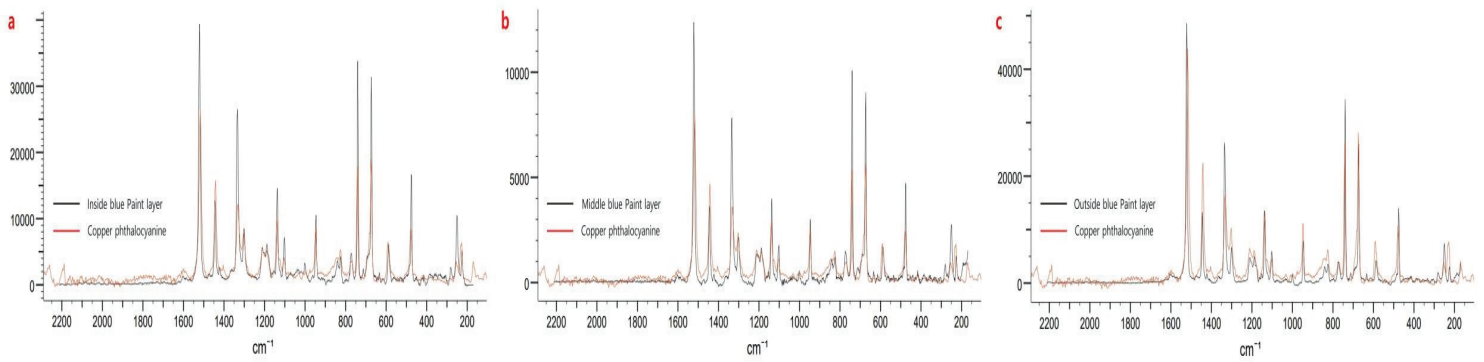

Figure 8. Raman spectra of blue paint layers. (a) Inside blue paint layer (sample c-1). (b) Middle blue paint layer (sample c-2). (c) Outside blue paint layer (sample c-3). 


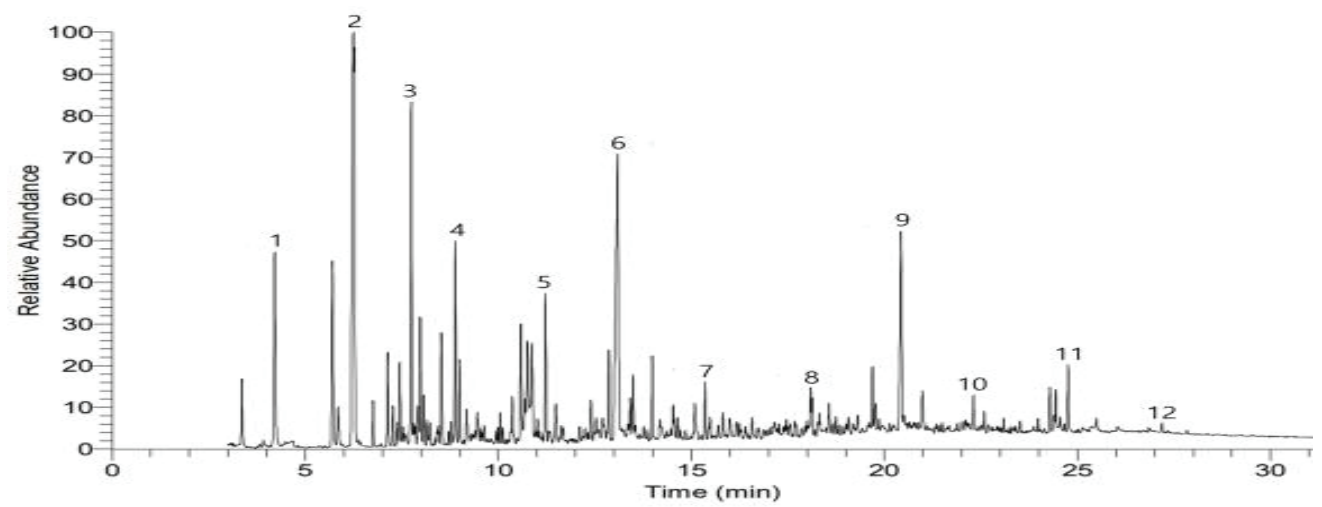

Figure 9. Pyrograrm of silver paint layer (sample a).

1: Toluene, 2: 1,3,5,7-Cyclooctatetraene, 3: à-Methylstyrene, 4: 9-brom anylbicyclo[4.2.1]nona-2,4,7-triene, 5: Naphthalene, 6: 1,2-Benzenedicar boxylic acid, 7: 1,1'-Biphenyl, 4-methyl-, 8: 1,2-Dihydroanthracene, 9: n-Hexadecanoic acid, 10: 6-[(2-Ethylhexyl)oxy]-6-oxohexanoic acid, 11: 2'-Deoxy-2'-methyleneadenosine, 12: 2,2,2-trifluoro-N-[5-methoxy-2(methoxymethyl)phenyl]acetamide.

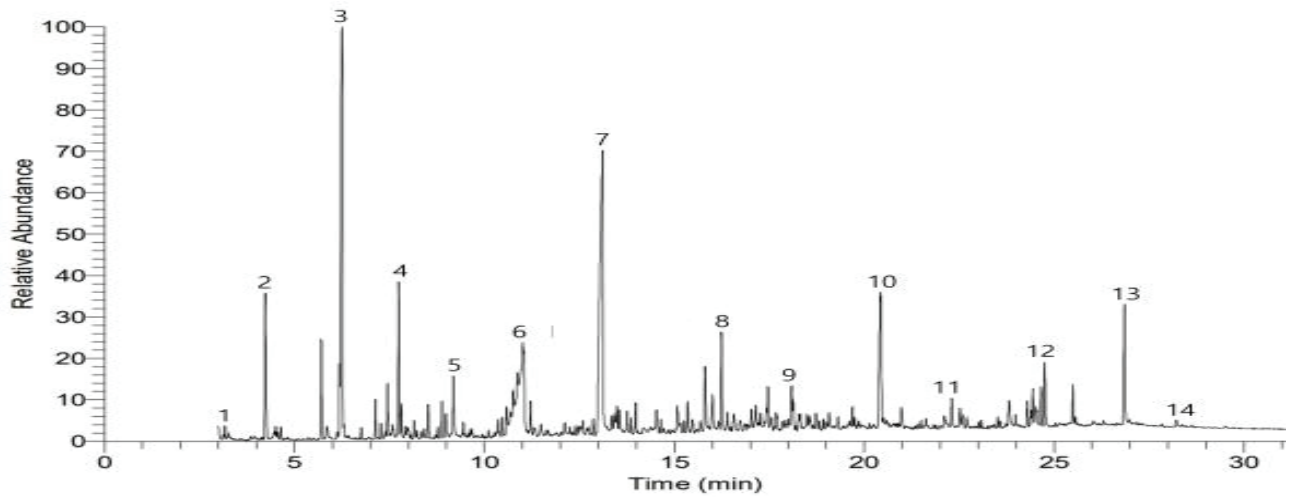

Figure 10. Pyrograrm of red paint layer (sample b).

1: Toluene, 2: 2-Butanone, 3: 1,3,5,7-Cyclooctatetraene, 4: à-Methylstyrene, 5: Acetophenone, 6: Benzoic acid, 7: Phthalic anhydride, 8: 5-benzo[e][1,3] benzoxazolesulfonic acid, 9: 4-phenyl-1,4-dihydro-2,3-benzoxathiine 3-oxide, 10: Dibutyl phthalate, 11: 2'-Deoxy-2'-methyleneadenosine, 12: 2,2,2-trifluoro-N-[5-methoxy-2-(methoxymethyl)phenyl] acetamide. 13: Bis(2-ethylhexyl) phthalate, 14: Benzo[b]phenanthridin- 5(6H)-one.

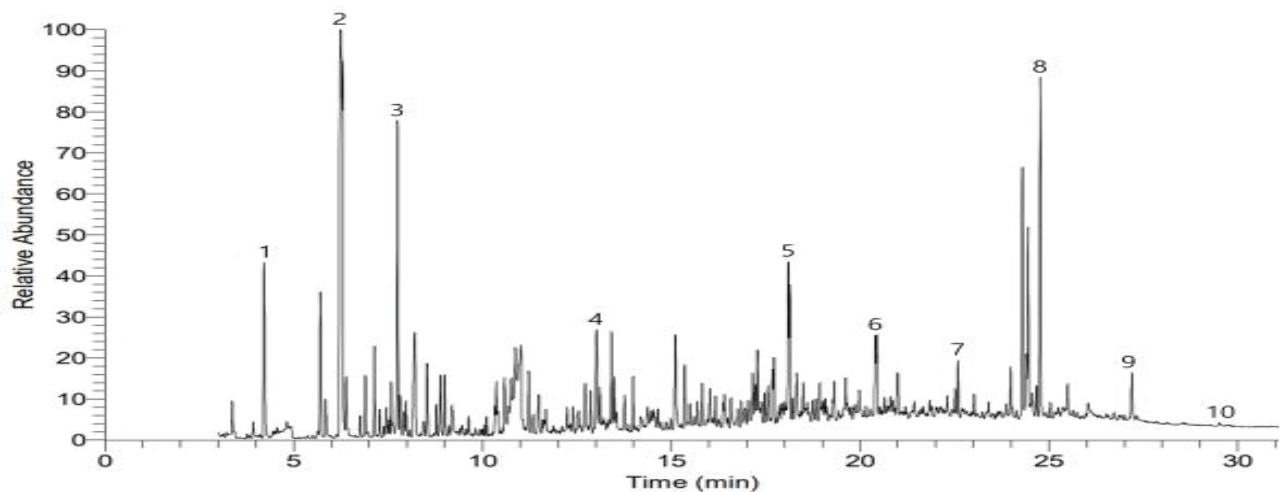

Figure 11. Pyrograrm of blue (inside) paint layer (sample c-1).

1: 2-Butanone, 2: Tetracyclo[3.3.0.0(2,4).0(3,6)]oct-7-ene, 3: Benzene, (1-methylethenyl)-, 4: Phthalic anhydride, 5: 4-phenyl-1,4-dihydro-2,3-benzoxathiine 3-oxide, 6: Dibutyl phthalate, 7: p-Terphenyl, 8: 2'-Deoxy-2'-methyleneadenosine, 9: 1,3-Benzenedicarboxylic acid, 10: 1,4-Benzenedicarboxylic acid. 


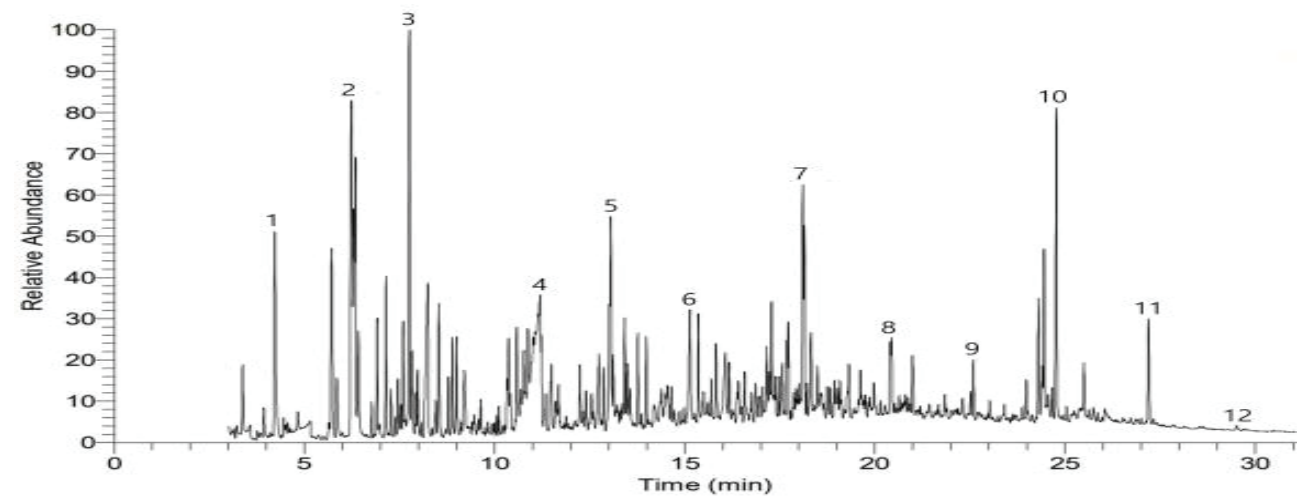

Figure 12. Pyrograrm of blue (middle) paint layer (sample c-2).

1: Toluene, 2: Styrene, 3: à-Methylstyrene, 4: Benzoic acid, 5: Phthalic anhydride, 6: Phthalimide, 7: 4-phenyl-1, 4-dihydro-2,3-benzoxathiine 3-oxide, 8: Dibutyl phthalate, 9: m-Terphenyl, 10: 2'-Deoxy-2'-methyleneadenosine, 11: 1,4-Benzenedicarboxylic acid, 12: 1,3-Benzenedicarboxylic acid.

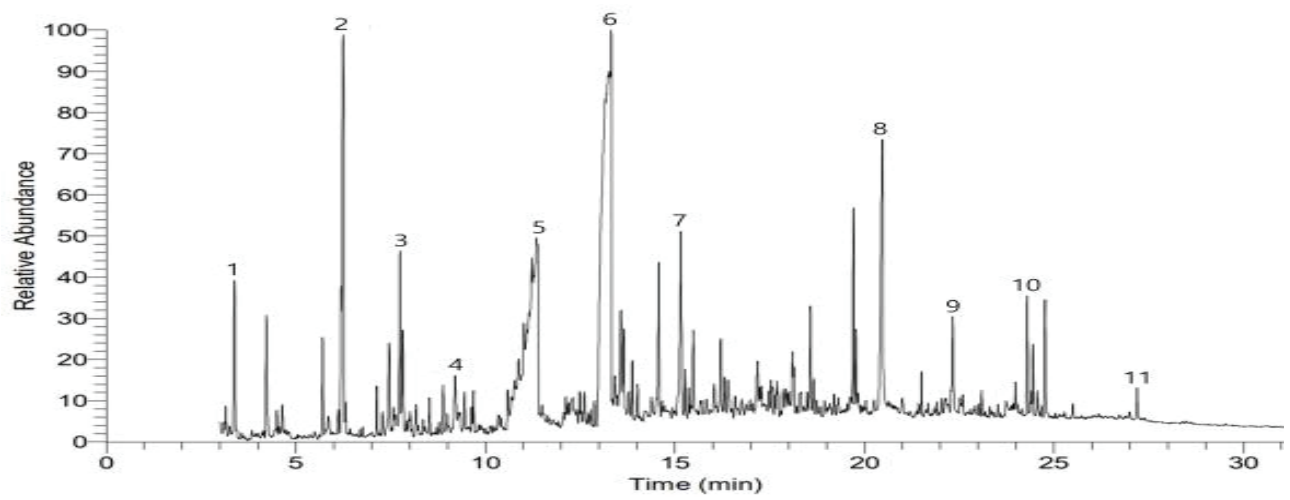

Figure 13. Pyrograrm of blue (outside) paint layer (sample c-3).

1: Methyl methacrylate, 2: Bicyclo[4.2.0]octa- 1,3,5-triene, 3: à-Methylstyrene, 4: Acetophenone, 5: Benzoic acid, 6: Phthalic anhydride, 7: 3-methyl-1-propyl-6,7,8,9-tetrahydro-5H-cyclohepta[c]pyridine, 8: n-Hexadecanoic acid, 9: Octadecanoic acid, 10: Hexanedioic acid, bis(2-ethylhexyl)ester, 11: 2'-Deoxy-2'-methyleneadenosine.

\section{CONCLUSION}

This study conducted an analysis of paint applied to the "Conversion" by the artist Na Myeong-gyu which is exhibited in the Busan Cheonmasan Sculpture Park through a scientific method of analysis aiming at securing basic data of the work that has been damaged continuously with the passage of time by being exposed to the outdoor environment. Currently, the work has been discolored and bleached by air pollutants and various environmental factors, and deterioration such as crack and exfoliation is also occurring, and especially, coupled response by ultraviolet rays in the atmosphere, moisture and oxygen is deforming binding of high molecule and causing continuous deterioration, so durability, water resistance, conservativeness and color applicability of paint have been weakened. Although exact record was not found, it is assumed that the work underwent repeated repainting.

To identify the foregoing, this study investigated layers of paint through the observation of cross section, and assumed ingredients of mineral pigment through the analysis of inorganic components, and examined ingredients of paint through FT-IR, Raman and GC-MS analysis. It is assumed that silver Sample a underwent two times of painting work, and painting was conducted using a paint that mixed aluminium powder with white pigment after primer and surfacer using materials such as kaolin, talc etc. As for the red Sample b, it was confirmed that painting was conducted using a paint mixed with toluidine red (Color of Art Pigment Database: Color Index (CI) name PR3, Molecular Formula: $\mathrm{C}_{17} \mathrm{H}_{13} \mathrm{~N}_{3} \mathrm{O}_{3}$ ), and 
is assumed that additional painting was made after two times of painting work. For putty used in the course of painting, calcium carbonate-based mixed materials were used and such putty work was confirmed to be carried out two times. As for blue, it is judged that a paint that mixed prussian blue (Color of Art Pigment Database: CI name PB27, Molecular Formula: $\mathrm{C}_{18} \mathrm{Fe}_{7} \mathrm{~N}_{18}$ ) with titanium white (Color of Art Pigment Database: CI name PW6, Molecular Formula: $\mathrm{O}_{2} \mathrm{Ti}$ ) was used for the initial painting, and similar paint was used for $2 \sim 3$ times after that. For additional painting, however, it was confirmed that a paint that mixed phthalocyanine blue (Color of Art Pigment Database: CI name PB15:1, Molecular Formula: $\mathrm{C}_{32} \mathrm{H}_{16} \mathrm{CuN}_{8}$ with titanium white was used.

As a result of analysis on the "Conversion", it was difficult to make a quantitative comparison due to the lack of analysis of paint and advanced researches on the status of damage etc., but this study was able to secure basic data that can be referred in establishing the directivity of conservative treatment and selection of materials in terms of conservation - management of works in the future. Continuous researches on the materials and technology for conservation shall be carried out simultaneously with secure of basic data through scientific analysis, and if a system that enables communication, cooperation and research activities with actual decision-makers such as artists, foundations and assistants is adopted, it is expected that data of this study can be used for maintaining intention of artist and originality of works, and securing conservativeness and communicability of works.

\section{REFERENCES}

Considine, B., Wolfe, J., Posner, K. and Bouchard, M., 2010, Conserving outdoor sculpture: The stark collection at the getty center. Getty Publications, Los Angeles, 125-126.
Huh, W.Y., 2009, Analysis of paint on Alxander Calder's 'Untitled-Swiss Cheese'. Samsung Museum Leeum, 5, 97-98. (in Korean with English abstract)

Kang, H,S., Kim, S.C. and Park, M.S., 2016, Characteristic analysis of paint used in defense industries equipments of Korean conflict in the War Memorial of Korea. Journal of Conservation Science, 32(2), 215-221. (in Korean with English abstract)

Kang, H.S., Jang, H.U., Kim, S.C. and Lee, U.C., 2020, Scientific analysis of national registered cultural heritage 666, Korea's first fighters used during the Korean War (F-51D). Conservation Science in Museum, 23, 71-90. (in Korean with English abstract)

Kim, K., 2014, Case studies on the conservation and restoration for artworks. Ph.D. dissertation, Hongik University, Seoul. (in Korean with English abstract)

Kim, S.C., Park, J.H., Jang, H.U., Choi, J.W. and Ahn J.Y., 2016, Conservation treatment of modern cultural heritage rickshaw. Journal of Conservation Science, 32(2), 203-213. (in Korean with English abstract)

Kim, S.C., Park, M.S. and Seo, J.H., 2012, Analysis of paint used in Streetcar No. 381 of registered culture property. Journal of Conservation Science, 28(3), 277-283. (in Korean with English abstract)

Kwon, H.H., Kim, J.H. and Han, Y.B., 2016, A study on conservation of outdoor painted sculptures: Niki de Saint Phalle's 'Black Nana'. Journal of Conservation Science, 32(3), 333-343. (in Korean with English abstract)

Michele, R.D., Dusan, C.S. and James, M.L., 1999, Infrared spectroscopy in conservation science. The Getty Conservation Institute, 14.

Oh, S.J. and Wi, K.C., 2020, An analysis of the characteristics of paint for preservation of painted works exhibited in the outdoor sculpture parks: Focusing on the works installed in Sculpture Parks in Jeollabuk-do area. Journal of Conservation Science, 36(5), 383-392. (in Korean with English abstract)

Son, T.M. and Lee, C.Y., 2008, Paint basic engineering, Donghwa Technology, Paju, 22-32. (in Korean)

Thomas, J.S.L, 2004, Analysis of modern paints. The Getty Conservation Institute, America, 81-116. 